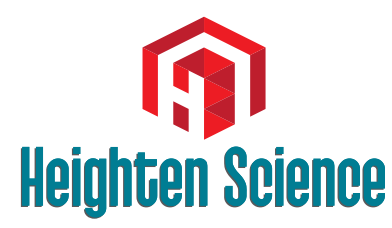

P U B L I C A T I O N S Corporation

\title{
Effect of diabetes mellitus on the Pulmonary Function Tests in Sudanese Diabetic Patients
}

\author{
Elmutaz H Taha', Ibrahim A Ali ${ }^{2 *}$ and Omer A Musa ${ }^{2}$ \\ 'Department of Physiology, Faculty of Medicine, Dongola University, Sudan \\ 2Department of Physiology, Faculty of Medicine, National Ribat University, Sudan
}

*Address for Correspondence: Ibrahim A Ali, Department of Physiology, Faculty of Medicine, National Ribat University, Sudan, Tel: 249912377276; Email: hemamedicine@gmail.com

Submitted: 21 August 2018

Approved: 28 August 2018

Published: 29 August 2018

Copyright: () 2018 Taha EH, et al. This is an open access article distributed under the Creative Commons Attribution License, which permits unrestricted use, distribution, and reproduction in any medium, provided the original work is properly cited

Keywords: FEV1; FVC; PFT; Diabetes mellitus

\section{Abstract}

Background: Diabetes mellitus is a leading cause of illness and death. Pulmonary function test PFT has assumed a key role in epidemiological studies investigating the incidence, natural history and causality of lung disease.

Methods: A cross sectional study was conducted in The National Ribat Teaching Hospital and Jabir Abualiz Specialized Diabetes Center in Khartoum state to measure the respiratory muscle power in 31 diabetic patients (case group) and 30 non-diabetics patients (control groups). Pulmonary function tests were measured by using Digital Spirometer-Micro-Plus version.

Results: lung function parameters between diabetic patients and their matched control group show no significant differences between the means of FVC, FEV1 and FEV1/FVC. However, diabetic patients showed significant reduction in PEFR.

Conclusion: Exercise and well control of diabetes helped in preserving normal respiratory muscle power. Continuous reasonable exercise with good control is highly recommended for all diabetics.

\section{Introduction}

Diabetes mellitus is a leading cause of illness and death. Lung function test is the most basic, widely used, pulmonary function test (PFT). It typically assesses lung volumes and flows and is ideally suited to describe the effects of obstruction or restriction on lung function [1]. It is now regarded as an integral component of any respiratory medical surveillance programs. PFT has assumed a key role in epidemiological studies investigating the incidence, natural history and causality of lung disease [2]. The role of lung function test in diabetic patients is further increased when a new strategy (Inhaled insulin) has been introduced for the treatment of diabetes mellitus [3]. In normal healthy non smoker subject after the age of 35, the expected decline in lung function, Forced Expiratory Volume in $1 \mathrm{sec}$ (FEV1) is 25-30 ml/year. However, the average rate of decline of lung function in diabetic patients as measured by Forced Expiratory Volume in $1 \mathrm{sec}$ (FEV1) is $71 \mathrm{ml} /$ year [4]. McKeever et al. [5], observed that increase in mean $\mathrm{HbA}_{1 \mathrm{c}}$ is associated with decrease in lung function parameters FVC \& FEV1. They hypothesized that impaired glucose auto-regulation is associated with impaired lung function.

In study of Sultan Meo et al., observed that Subjects with diabetes showed a significant reduction in forced vital capacity (FVC) and forced expiratory volume in the first second (FEV1) relative to their matched controls, concluded that Pulmonary function in a specific ethnic group of patients with diabetes was impaired as evidenced by a decrease in FVC and FEV1 compared to pulmonary function in matched controls. Stratification of results by years of disease revealed a significant correlation between duration of disease and a decline in pulmonary function [6]. In other study of Ali Mo et 
al., demonstrated that mean of the percentage of the predicted values of FVC and FEV1, were significantly $(\mathrm{p}<0.001)$ lower in diabetic patients than their matched. Again they concluded that the ventilatory function of lung may be reduced in type 2 diabetes which may be related to the duration of the disease [7]. For this reason respiratory muscle endurance also decreases in diabetes mellitus [6]. Again, the increased ratio of FEV1/FVC (\%) in diabetic patients of longer duration is due to disproportionate reduction of FVC and FEV1, which indicate that long-standing hyperglycemia may cause predominantly restrictive type of lung disorder. All these changes may be due to glycation of the chest wall and bronchial tree protein. This is further supported by negative correlation of FVC and FEV1 and positive correlation of FEV1/FVC\% with longer duration of diabetes. The negative correlation of FVC and FEV1 with duration of diabetes indicate that long standing hyperglycemia may intensify the devastating effect of the disease [6].

The present study was designed to observe the effect of diabetes mellitus on lung function in patients with diabetes mellitus belonging to specific society namely Sudanese in the center of Sudan.

\section{Materials and Methods}

A cross sectional study was conducted to measure the pulmonary function tests in 31 diabetic patients (case group) and 30 non-diabetics patients (control groups). The study was conducted in The National Ribat Teaching Hospital and Jabir Abualiz Specialized Diabetes Center which are located in Khartoum state - the capital of Sudan. This study group includes all Sudanese diabetic patients attending to the diabetic clinics in The National Ribat Teaching Hospital and Jabir Abualiz Specialized Diabetes Center during the period of study. Age range from 20 to 75 years, and mean duration of disease was $10.60 \pm 1.11$ years. Their duration of disease ranged from 1 to 30 years. Patients with diabetes were individually matched with controls for age, height, and weight. Matching between both groups was within \pm 3 years for age, \pm 4 centimeters for height, and \pm 5 kilograms for weight. Overall, there were no significant differences in anthropometric means in combined or stratified data. Age, and height were given more emphasis for matching, as these two relate better to lung function than weight.

11 Controls were from a similar community with the same socioeconomic status relative to patients with diabetes. All subjects had never smoked. All subjects completed a questionnaire, which included anthropometric data and a consent form. Subjects with gross abnormalities of the vertebral column or thoracic cage, known history of acute or chronic respiratory infections, neuromuscular disease, malignancy, cardiopulmonary disease, or a history of major abdominal or chest surgery were excluded from the study. In addition, subjects with current or previous drug or tobacco (smoked or chewed) addictions were excluded. Patients with complications of diabetes such as neuropathy, nephropathy, and retinopathy were also excluded from the study.

\section{Technique of pulmonary function tests}

A spirometer is an apparatus for measuring the volume of air inspired and expired by the lungs; (Figure 1). The subject was asked to take a deep breath (maximum inspiration), and expire hard and forcible as long as possible into the spirometer. The tests were performed (with each subject in the standing position). The tests were repeated three times after adequate rest. Patients were trained about the entire maneuver and were encouraged to practice this maneuver before doing the pulmonary function tests. The parameters that were measured included force vital capacity (FVC), force expiratory volume in 1 second (FEV1), FEV1/FVC, and peak expiratory flow rate (PEFR) the best reading of the three was taken.

\section{Data analysis}

Data was analyzed by statistical package for social science (SPSS) version 20, and any significance different between case and control groups in pulmonary function tests were identified by using t- test among sociodemographic and medical characteristic. Data had been displayed by tables and histogram. 


\section{Ethical clearance}

Ethical clearance was obtained from the scientific committee of the university and from the Hospital.

\section{Results}

In this study 61 adult subjects were included, $54.10 \%$ (34) male, and $45.9 \%$ (27) female. 31 diabetic (17 males and 14 females) and 30 control (17 male and 13 female) Figure 2.

Figure 3 showed that most of the subjects $37.7 \%$ (23 subjects) were in the age group 51-60 years, $32.8 \%$ (20 subjects) were in the age group $41-50$ years and $29.5 \%$ (18 subjects) were in the age group 30-40 years.

Figure 4 showed that most of diabetic patients $74.2 \%$ (23 patients) included in this study have DM for 1-5 years. Patients with DM for more than 10 years (3 patients) have been well controlled on regular treatment and perform exercise daily for at least one-hour walking for the last 10 years compared to the rest.

Table 1 Summarizes the comparison of lung function parameters between diabetic patients and their matched control group. There were no significant differences between the means of FVC, FEV1 and FEV1/FVC. However, diabetic patients showed significant reduction in Peak Expiratory flow rate PEFR.

Table 2 Summarizes the comparison of lung function parameters between diabetic patients with duration of disease 1-10 years and their matched control group. There were no significant differences between the means of FVC, FEV1 and FEV1/FVC. However, diabetic patients showed significant reduction in PEFR.
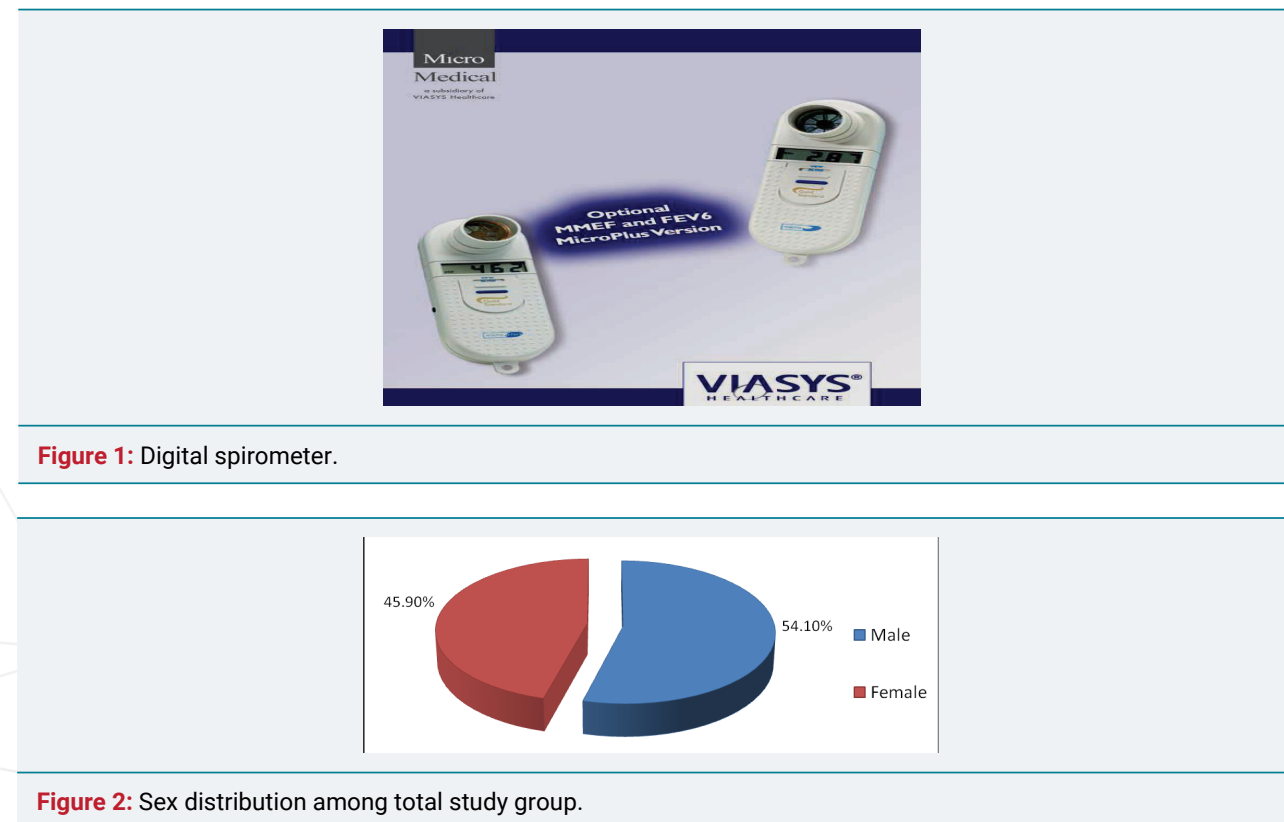

Figure 2: Sex distribution among total study group.

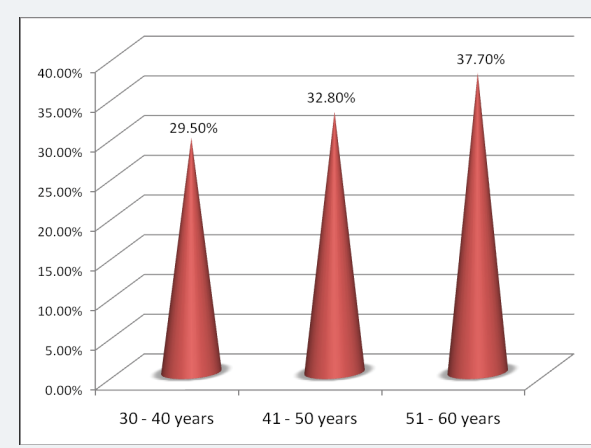

Figure 3: Age distribution among study population. 


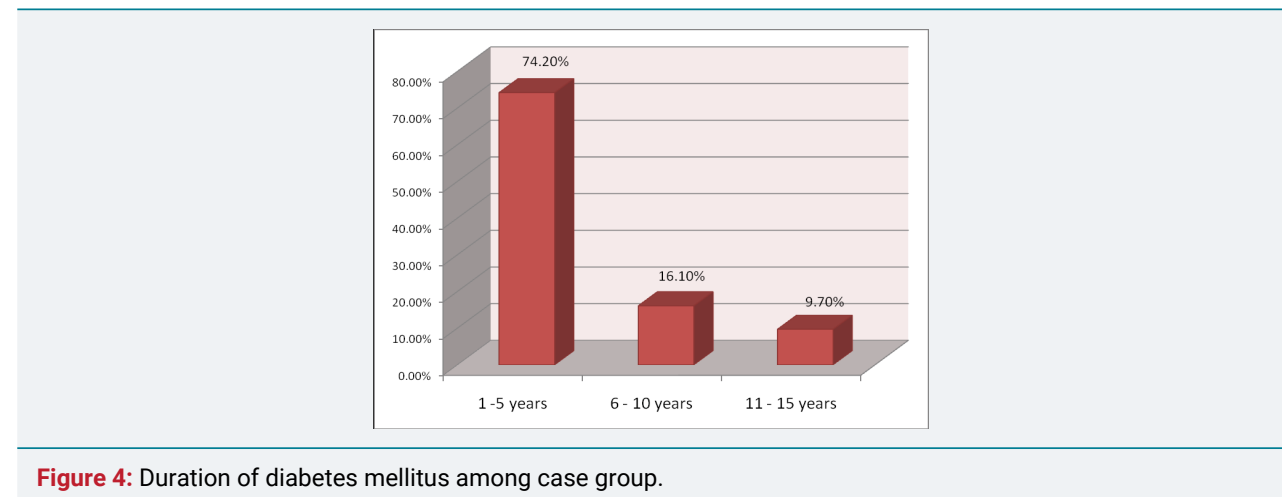

Table 1: lung function and anthropometric data of total diabetic patients (31) compared with their matched controls (30).

\begin{tabular}{|c|c|c|c|c|}
\hline Parameters & $\begin{array}{c}\text { DM } \\
\text { mean +- SEM } \\
n(31)\end{array}$ & $\begin{array}{c}\text { Control } \\
\text { Mean +- SEM } \\
\text { n (30) }\end{array}$ & P. value & \\
\hline Age (years) & $36.1+-7.47$ & $36.8+-6.81$ & 0.823 & Ns \\
\hline Height (cm & $168.73+-2.142$ & $168+-9.243$ & 0.930 & Ns \\
\hline Weight (kg & $70.7+-3$ & $78.233+-2.25$ & 0.121 & Ns \\
\hline FVC (L) & $3.26+-0.147$ & $3.38+-0.135$ & 0.751 & Ns \\
\hline FEV1 (L) & $2.65+-0.13$ & $2.714+-0.117$ & 0.74 & Ns \\
\hline PEFR (L) & $322.66+-25.7$ & $368.53+-23$ & 0.03 & $S$ \\
\hline FEV1/FVC (\%) & $90.6+-1.261$ & $89.2+-1.024$ & 0.756 & Ns \\
\hline
\end{tabular}

Table 2: show the lung function and anthropometric data for diabetic patients with duration of disease 1-10 years compared with their matched controls.

\begin{tabular}{|c|c|c|c|c|}
\hline & $\begin{array}{c}\text { DM } \\
\text { Pean +- SEM } \\
\mathbf{n}(\mathbf{2 8})\end{array}$ & $\begin{array}{c}\text { Control } \\
\text { Mean +- SEM } \\
\mathbf{n}(\mathbf{3 0})\end{array}$ & P. value \\
\hline Age (years) & $35.75+-7.47$ & $36.8+-6.81$ & 0.786 & Ns \\
\hline Height (cm & $164.65+-2.142$ & $168+-9.243$ & 0.430 & Ns \\
\hline Weight (kg & $69.4+-3$ & $78.233+-2.25$ & 0.101 & Ns \\
\hline FVC (L) & $3.00+-0.147$ & $3.38+-0.135$ & 0.751 & Ns \\
\hline FEV1 (L) & $2.62+0.13$ & $2.714+0.117$ & 0.63 & Ns \\
\hline PEFR (L) & $287.82+-25.7$ & $368.53+-23$ & 0.009 & S \\
\hline FEV1/FVC (\%) & $89.25+1.261$ & $89.9+-1.024$ & 0.756 & Ns \\
\hline
\end{tabular}

Table 3 Summarizes the comparison of lung function parameters between diabetic patients with duration of disease 1-5 years and their matched control group. There was no significant differences between the means of FVC, FEV1 and FEV1/FVC. However, diabetic patients showed a significant reduction in PEFR.

There were no significant differences between the means of the lung function parameters of diabetic patients according to the duration of disease from 6 to 10 years compared with their matched control (Table 4).

Diabetic patients with duration of disease more than 10 years showed a significant increase in $\mathrm{FEV}_{1}$ compared to their matched control. However, there was no significant difference in pulmonary function and anthropometric data (Table 5).

Figure 5 showed the average mean of PEF between diabetics and control.

Exercise activity in case group (diabetic) was low with percentage $45.2 \%$ (14 patients), while $54.8 \%$ (17 patients) are not performing exercise (Figure 6).

Patients, who perform exercise, walk for half an hour, but not regularly. However, three patients with duration of disease more than 10 years perform exercise (walking) for at least one hour daily for more than 10 years.

Depending on exercise performance diabetic patients those practice exercise showed slight increase (not significance) in all pulmonary function data as shown in table 6. 
Table 3: lung function and anthropometric data for diabetic patients with duration of disease 1-5 years compared with their matched controls.

\begin{tabular}{|c|c|c|c|c|}
\hline Parameters & $\begin{array}{c}\text { DM } \\
\text { mean +- SEM } \\
n(23)\end{array}$ & $\begin{array}{c}\text { Control } \\
\text { Mean +- SEM } \\
\text { n (30) }\end{array}$ & P. value & \\
\hline Age (years) & $35.1+-7.47$ & $36.8+-6.81$ & 0.723 & Ns \\
\hline Height (cm & $166.7+-2.142$ & $168+-9.243$ & 0.630 & Ns \\
\hline Weight (kg & $74+-3$ & $78.233+-2.25$ & 0.221 & Ns \\
\hline FVC (L) & $2.88+-0.147$ & $3.38+-0.135$ & 0.451 & Ns \\
\hline FEV1 (L) & $2.566+-0.13$ & $2.714+-0.117$ & 0.4 & Ns \\
\hline PEF (L) & $260.261+-25.7$ & $368.53+-23$ & 0.003 & $S$ \\
\hline FER (\%) & $88.7+-1.261$ & $89.9+-1.024$ & 0.756 & Ns \\
\hline
\end{tabular}

Table 4: lung function and anthropometric data for diabetic patients with duration of disease from 6-10 years compared with their matched controls.

\begin{tabular}{|c|c|c|c|c|}
\hline Parameters & $\begin{array}{c}\text { DM } \\
\text { Mean +- SEM } \\
\mathbf{n}(5)\end{array}$ & $\begin{array}{c}\text { Control } \\
\text { Mean +- SEM } \\
\mathbf{n}(\mathbf{3 0})\end{array}$ & P. value & \\
\hline Age (years) & $36.4+-9.55$ & $36.8+-6.81$ & 0.920 & $\mathrm{Ns}$ \\
\hline Height (cm) & $162.6+-6.57$ & $168+-1.7$ & 0.275 & $\mathrm{Ns}$ \\
\hline Weight (kg) & $64.8+-3.33$ & $78.23+-2.251$ & 0.025 & $\mathrm{~S}$ \\
\hline FVC (L) & $3.124+-0.4465$ & $3.381+-0.134$ & 0.820 & $\mathrm{Ns}$ \\
\hline FEV1 (L) & $2.686+-0.381$ & $2.714+-0.117$ & 0.931 & $\mathrm{Ns}$ \\
\hline PEFR (L) & $315.4+-67$ & $368.53+-23$ & 0.402 & $\mathrm{NS}$ \\
\hline FEV1/FVC (\%) & $89.8+-4.17$ & $89.9+-1.03$ & 0.842 & $\mathrm{Ns}$ \\
\hline
\end{tabular}

Table 5: Anthropometric and lung function data among diabetic patients with duration of disease more than 10 years compared with matched control.

\begin{tabular}{|c|c|c|c|c|}
\hline Parameters & $\begin{array}{c}\text { DM } \\
\text { mean+-SEM } \\
\mathbf{n}(\mathbf{3})\end{array}$ & $\begin{array}{c}\text { Control } \\
\text { Mean+- SEM } \\
\mathbf{n}(\mathbf{3 0})\end{array}$ & P. value & \\
\hline Age (years) & $36.8+-81$ & $34.2+-9.81$ & 0.832 & Ns \\
\hline Height (cm) & $175.6+-4.33$ & $168.0+-1.68$ & 0.170 & Ns \\
\hline Weight (kg) & $73.33+-0.88$ & $78.23+-2.23$ & 0.503 & Ns \\
\hline FVC (L) & $3.896+-0.18$ & $3.38+-0.134$ & 0.057 & Ns \\
\hline FEV1 (L) & $3.673+-0.3$ & $2.714+-0.117$ & 0.018 & $\mathrm{~S}$ \\
\hline PEFR (L) & $492.33+-68.3$ & $368.53+-23$ & 0.112 & $\mathrm{NS}$ \\
\hline FEV1/FVC (\%) & $93.33+-3.84$ & $89.9+-1.03$ & 0.241 & $\mathrm{Ns}$ \\
\hline
\end{tabular}

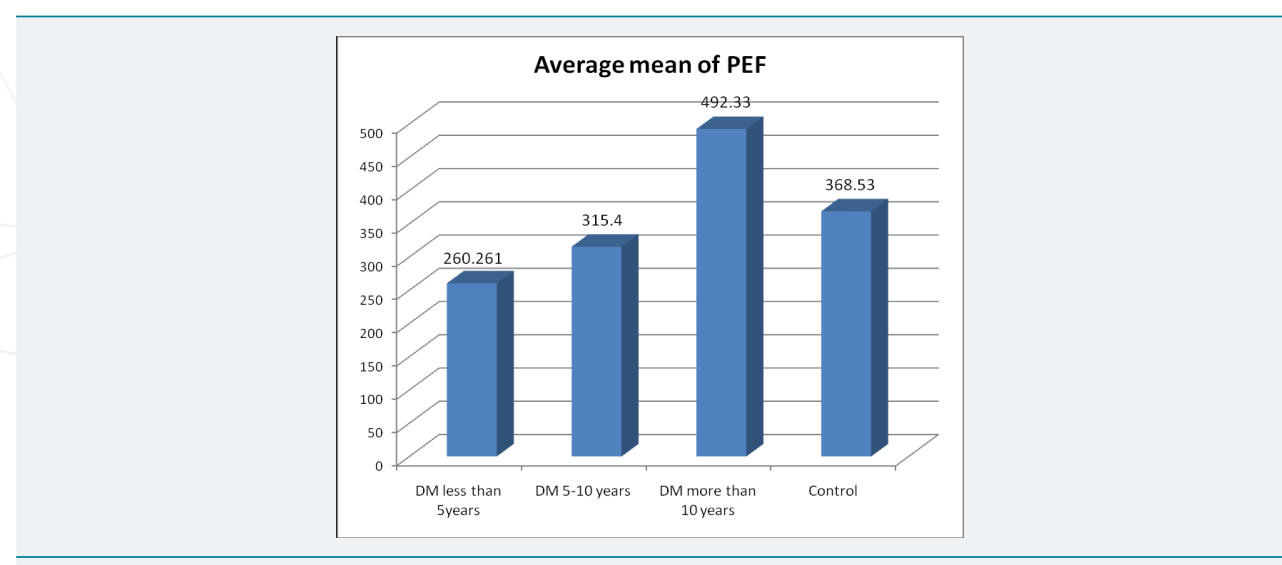

Figure 5: The average mean of PEF among diabetics with different duration and control group.

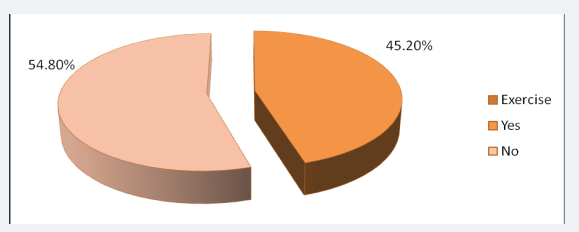

Figure 6: Exercise performance among diabetic patients. 
There was no significant difference among the means of lung function parameters between the diabetic patients with exercise performance compared with their matched control as shown in table 7.

Depending on exercise performance diabetic patients without exercise performance revealed a significant reduction in PEFR compared with their matched control as shown in table 8.

According to vitamin supplementary most of the diabetic patients $61.30 \%$ (19 patients) don't use vitamin, while $38.70 \%$ (12 patients) use vitamin regularly as shown in figure 7.

Table 9 illustrated there were no significant differences in lung function parameters among diabetics patients according to vitamin supplementary. Although there is slight increase in those with vitamin supplementary.

\section{Discussion}

This study was conducted among type II diabetic patients (31) and their control (30). The results showed that diabetic patients with duration of disease less than 5 years, there was a significant reduction in the PEFR $(260.2+-25.7) \mathrm{p}$ value $<0.05$ compared to their control group (368.5+-23), which is not in agreement with study of sultan Meo et al. [6], who reported that there was no significant difference between the means of any lung function data among diabetics and their control.

\begin{tabular}{|c|c|c|c|c|}
\hline Exercise & $\begin{array}{c}\text { Yes } \\
\text { Mean }^{+} \text {SEM } \\
\mathrm{N}(14)\end{array}$ & $\begin{array}{c}\text { Control } \\
\text { Mean +- SEM } \\
\mathrm{n}(30)\end{array}$ & P. value & \\
\hline $\mathrm{FVC} \mathrm{(L)}$ & $3.26+-.2$ & $3.381+-.134$ & .621 & Ns \\
\hline FEV1 (L) & $2.953+-.2$ & $2.714+-.117$ & .462 & Ns \\
\hline PEF (L) & $342.714+-39.87$ & $368.53+-23$ & .168 & Ns \\
\hline FEV1/FVC (\%) & $91.28+-1.67$ & $89.9+-1.03$ & .534 & Ns \\
\hline
\end{tabular}

Table 8: Lung function data among diabetic patients without exercise performance compared with their matched control.

\begin{tabular}{|c|c|c|c|c|}
\hline \multicolumn{1}{|c|}{$\begin{array}{c}\text { No } \\
\text { Mean+_SEM } \\
\mathbf{N}(\mathbf{1 7})\end{array}$} & $\begin{array}{c}\text { Control } \\
\text { Mean +- SEM } \\
\mathbf{n}(\mathbf{3 0})\end{array}$ & \multicolumn{2}{c|}{ P. value } \\
\hline Parameters & $2.852+-0.18$ & $3.381+-.134$ & 0.08 & Ns \\
\hline FVC (L) & $2.47+.152$ & $2.714+-.117$ & 0.082 & Ns \\
\hline FEV1 (L) & $249.5+-30.32$ & $368.53+-23$ & 0.05 & $\mathrm{~S}$ \\
\hline PEFR (L) & $87.70+-1.95$ & $89.9+-1.03$ & 0.334 & Ns \\
\hline FEV1/FVC (\%) & & &
\end{tabular}

Table 9: vitamin supplementary among diabetic patients.

\begin{tabular}{|c|c|c|c|c|}
\hline Parameters & $\begin{array}{c}\text { Yes } \\
\text { Mean +-SEM } \\
\mathbf{n}(12)\end{array}$ & $\begin{array}{c}\text { No } \\
\text { Mean +-SEM } \\
\text { n (19) }\end{array}$ & P. value & \\
\hline $\mathrm{FVC}(\mathrm{L})$ & $3.064+-0.224$ & $2.99+-0.182$ & 0.813 & Ns \\
\hline FEV1 (L) & $2.695^{+-} 0.198$ & $2.69+-0.170$ & 0.983 & Ns \\
\hline $\operatorname{PEFR}(\mathrm{L})$ & $309.916+-36.908$ & $280.052^{+}-35.039$ & 0.578 & Ns \\
\hline FEV1/FVC (\%) & $89.33^{+}-2.129$ & $89.315^{+}-1.432$ & 0.994 & Ns \\
\hline
\end{tabular}

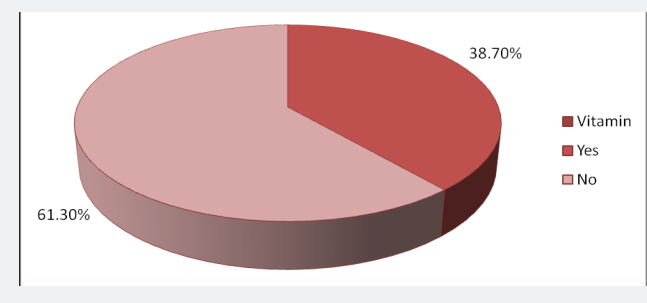

Figure 7: Vitamin supplementary status among diabetic patients. 
On the other hand this finding in agreement of our study Ali, Mo et al. [7], reported that the mean percentage of predicted values of FVC and FEV1 in diabetics were significantly lower than their control. McKeever $\mathrm{T}$ et al. [5], showed the same result as they observed that increase in mean $\mathrm{HbA}_{1 \mathrm{c}}$ is associated with decrease in lung function parameters FVC \& FEV1. They hypothesized that impaired glucose auto- regulation is associated with impaired lung function.

Diabetic patients with duration of disease from 5 to 10 years revealed no obvious reduction in all pulmonary functions data compared to their control, which is not in the same line of Sultan Meo et al., who reported that patients with diabetes did show a significant reduction in FVC. On the other hand in diabetics according to the duration more than 10 years of disease showed a significant increase ( $p$ value a.o5) in the average means of FEV1 (3.673+-0.3) compared to their matched control (2.714+-0.117), This finding is not in agreement with findings of Sultan Meo et al., who showed that there was a significant decline in FVC and FEV1 in type 2 diabetic patients. However, Ali Mo et al., demonstrated that diabetic patients with duration of disease more than 10 years had a significant high percentage of PEFR compared to their matching control, which is in disagreement to our result showed that there were no significant differences between diabetic patients and their control in the predicted value of PEFR. According to exercise diabetic subjects without exercise performance showed slight increase (not significant) in pulmonary function data. This is in agreement with the findings of Leem Romer et al. [9], who reported that in athlete's racing bicycle, respiratory muscle power was increased by $35 \mathrm{~W}$ every 3 min starting from $95 \mathrm{~W}$.

No significant values were obtained in diabetic patients with vitamin supplementary on the pulmonary function tests compared with diabetic patients without vitamin supplementary. As the number is limited, more diabetic should be included in another study.

\section{Conclusion}

Exercise and well control of diabetes helped in preserving normal respiratory muscle power. This could be considered a pilot study and more investigation of more numbers of DM with different duration of disease and level of exercise needs to be performed. Continuous reasonable exercise with good control is highly recommended for all diabetics.

\section{References}

1. Ruppel GL. Pulmonary function testing. Trends and techniques. Resp Care Clinics. 1997; 3: 155-181.

2. Ray MT, Edward HP. Pulmonary function testing in industry. In: Occupational Medicine. Edited by Carl, Zenz O, Bruca Dickerson. Edward HP. Mosby London, Third edition, 1984; 229.

3. Meo SA, Al-Drees AM, Arif M, Al-Rubean K. Lung function in type 2 Saudi diabetic patients. Saudi Med J. 2006; 27: 338-343. Ref.: https://tinyurl.com/yc96m4mx

4. Davis WA, Knuiman $M$, Kendall $P$, Grange $V$, Davis $M$, et al. Glycemic exposure is associated with reduced pulmonary function in type 2 diabetes: the Fremantle Diabetes Study. Diabetes Care. 2014; 27: 752-757. Ref.: https://tinyurl.com/yc5v7wpr

5. McKeever T, Weston P, Hubbard R, Fogarty A. Lung Function and Glucose Metabolism: An Analysis of Data from the Third National Health and Nutrition Examination Survey. Am J Epidemiol. 2005; 161: 546-556. Ref.: https://tinyurl.com/y8cy7fam

6. Meo SA, Al Drees AM, Ahmed J, Ahmed Shah SF, Al-Regaiey K, et al. Effect of Duration of Disease on Ventilatory Function in an Ethnic Saudi Group of Diabetic Patients. J Diabetes Sci Technol. 2007; 1: 711-717. Ref.:https://tinyurl.com/y7a7mxja

7. Ali MO, Begum S, Begum N, Ali T, Ferdousi S, et al. FVC, FEV1 and FEV1/FVC\% in Type 2 Diabetes and Their Relationships with Duration of the Disease. J Bangladesh Soc Physiol. 2009; 4: 81-87. Ref.: https://tinyurl.com/y9ncwumb

8. Park SW, Goodpaster BH, Strotmeyer ES, Rekeneire N, Harris TB, et al. Decreased Muscle Strength and Quality in Older Adults with Type 2 Diabetes: The Health, Aging and Body Composition Study. Diabetes. 2006; 55: 1813-1818. Ref.: https://tinyurl.com/ycardd5r

9. Tobin MJ, Chadha TS, Jenouri G, Birch SJ, Gazeroglu HB, et al. Breathing patterns: 2. Diseased subjects. Chest. 1983; 84: 286-294. Ref.: https://tinyurl.com/ydgvp3wj 